\title{
Dermatomyositis as initial presentation of Hodgkin's lymphoma: A case report and review of literature
}

\author{
Pannu $\mathrm{AK}^{1 *}$, Varma $\mathrm{SC}^{1}$ \\ ${ }^{1}$ Department of Internal Medicine, Post Graduate Institute of Medical Education and Research, Chandigarh, India
}

Received: 11 November, 2016; Accepted: 5 December, 2016; Published: 10 December, 2016

*Corresponding author: Ashok kumar Pannu, Department of Internal Medicine, Post Graduate Institute of Medical Education and Research, Chandigarh, India, Tel no: +919914291115; E-mail: gawaribacchi@gmail.com

\section{Introduction}

The increased incident of malignancy is well established in patients with inflammatory myopathies and specifically in Dermatomyositis (DM). However, the association between DM and Hodgkin's Disease (HD) is very unusual. We have recently had the opportunity of observing a patient who manifested the clinical features of DM and found to have HD after a detailed work up.

\section{Case report}

This 30 year old lady presented with history of fever for 2 months, which was initially low grade but later increased up to $104 \mathrm{~F}$. Fever was intermittent and associated with night sweats. She had polyarthralgia involving bilateral symmetrical hand joints, wrists, knees and ankles but without swelling or early morning stiffness. She had characteristic skin lesions of DM including heliotrope eruption with violaceous erythema and mild edema of upper eyelids, erythematous to violaceous papules and plaques over both knuckles (Gottron's papules), erythematous rash over upper chest (V sign) and upper back (shawl sign) and photosensitive papules over forearms and dorsum of hands.

On examination she had pallor, cervical and axillary lymphadenopathy and hepatosplenomegaly. Joint examination did not reveal active synovitis. Motor examination showed muscle power of $4 / 5$ at hip flexion and extension. Rest of the limb and neck muscles were strong. Deep tendon reflexes were $2+$ and bilateral plantars were flexor.

Investigation showed anemia with hemoglobin of $6.5 \mathrm{~g} / \mathrm{dl}$ and peripheral blood film revealed normocytic normochromic to microcytic hypochromic red cells. Renal function test, liver function test and serum calcium were normal. Liver was $17.5 \mathrm{~cm}$ and spleen was $16.9 \mathrm{~cm}$ in size on ultrasonography.

Lactate Dehydrogenase (LDH) was 3880 U/L (reference values 240-480), Creatinine Kinase - Skeletal Muscle (CK-MM) was $344 \mathrm{U} / \mathrm{L}$ (reference values 10-165) and Electromyography (EMG) from right vastus lateralis and deltoid showed myopathic pattern. A muscle biopsy showed foci of perivascular lymphomononuclear inflammatory infiltrate with fiber regeneration and few of the fibers show muscle fiber splitting. Overall features were suggestive of myopathy pattern.
Skin biopsy from dorsum of hand lesion showed basal cell vacuolar degeneration with occasional apoptotic keratinocytes in epidermis and mild perivascular chronic inflammatory cells, consistent with DM.

On the basis of characteristic skin rash distribution, elevated muscle enzymes (CK-MM, LDH), EMG, skin and muscle biopsy, a diagnosis of DM was made according to Bohan and Peter classification criteria. ${ }^{[1,2]} \mathrm{DM}$ associated connective tissue disease (rheumatoid arthritis, systemic lupus erythematosus, systemic sclerosis, Sjogren syndrome, mixed connective tissue disease) work up was negative. Anti-Jo1 antibody was negative and spirometry and computed tomography of chest did not show features of interstitial lung disease.

Work up for associated malignancy was carried out. Breasts and pelvis were normal on physical examination and on ultrasonography. In view of presence of lymphadenopathy and hepatosplenomegaly, a possibility of lymphoma was kept and a whole-body Positron Emission Tomography (PET) scan was done which showed generalized lymphadenopathy (bilateral cervical, bilateral axillary, bilateral hilar, peripancreatic, splenic, aortocaval, paraortic, bilateral common iliac, internal and external iliac and bilateral inguinal lymph nodes) with a possibility of lymphomatous etiology. Left cervical lymph node fine needle aspiration cytology and right axillary lymph node biopsy showed reactive lymphoid hyperplasia. Bone marrow biopsy and splenic aspirate cytology were also suggestive of reactive changes. In view of a high possibility of lymphoma, a repeat lymph node biopsy from right cervical region was done which was consistent with HD, nodular sclerosis. Ann Arbor staging was stage IV S B and ECOG (Eastern Cooperative Oncology Group) performance scale was 2. For HD ABVD (doxorubicin, bleomycin, vinblastin and dacarbazine) regimen was given and for dermatomyositis, she was started on oral prednisolone $1 \mathrm{mg} / \mathrm{kg}$ and topical fluticasone (for skin lesions). Following these measures, her fever subsided, skin lesions improved and performance scale improved to ECOG 1 and LDH decreased to $1590 \mathrm{U} / \mathrm{L}$ on a subsequent outpatient follow up.

\section{Discussion}

DM is a systemic inflammatory myopathy characterized by 
symmetrical proximal muscle weakness with characteristic skin lesions along with specific muscle biopsy findings, elevation of serum muscle enzymes and typical EMG findings.

HD is a mature B-cell-derived cancer and is characterized by lymphadenopathy with or without fever, weight loss and night sweating. The diagnosis is established by histopathological examination of an adequate biopsy specimen.

The association between DM and malignancy is well documented and Standardized Incidence Ratios (SIRs) are 3.0 to $12.6 . .^{[3,5]}$ The most common tumors associated with DM are ovarian cancer, breast cancer, melanoma, colon cancer, and Non-Hodgkin's Lymphoma (NHL). HD is an uncommon associated malignancy. A recent study showed that in patients with autoimmune diseases the overall risk to develop HD was significantly increased (SIR -2.0) and DM patients had an increased risk to develop HD (SIR- 6.3) . ${ }^{[6]}$

The immunological disturbance and high inflammatory activity in autoimmune diseases is the major risk for development of lymphoma. ${ }^{[7]}$ However, treatment with immunosuppressive therapy may also play a role in some cases. ${ }^{[8]}$

A MEDLINE search of the literature tracked a total of 16 adult patients with diagnoses of both DM and HD (Table 1). Patient sex distribution was 10 females and 6 males. There is no clear sex preponderance of these diseases.

The age range of patients reviewed ranged from 23 to 71 years (mean age 47.12 years; median age 48.50 years) i.e., similar to patients with DM without malignancy. ${ }^{[27,28]}$
In all the cases, clinical features of DM appeared before or concomitant with the manifestation of HD, but never after. Temporal association does not imply a cause-effect relationship, however, the longer the time interval between the two diagnoses, the weaker becomes the correlate. Most solid cancers develop within one year of the onset of DM, although the risk for malignancy remains high for up to five years after a diagnosis of DM was established. ${ }^{29]}$

The clinical features of DM are similar in the three groups of patients - those with no associated malignancy, those with HD, and those with other malignancies.

Regarding the extent and staging of the HD, eight patients (and index case) had stage III or IV and this proportion was higher than in a population with HD alone. Four patients had stage I-II and for four patients no stage was stated. It has been postulated that the advanced stage can be due to delay in the clinical diagnosis of the HD by steroid, started for the treatment of DM ${ }^{[21]}$. However the HD stage mentioned in the case reports is not necessarily is stage at initial diagnosis.

Oral corticosteroids were used for DM in the majority of the cases. Regarding the treatment of HD, three patients (and the present case) were treated with MOPP/ ABVD chemotherapy, two with chemotherapy other than MOPP/ ABVD, one patient with MOPP and radiotherapy, two with nitrogen mustard and radiotherapy, three patients with radiotherapy only and two with corticosteroid and other cytotoxic drugs; two patients received no treatment. In one case where HD developed during methotrexate therapy, tumor disappeared after removal of the drug.

\begin{tabular}{|c|c|c|c|c|c|c|}
\hline Reference & Age/sex & $\begin{array}{l}\text { Interval between the } \\
\text { diagnoses } \\
\text { (DM } \rightarrow \text { HD) }\end{array}$ & Treatment of DM & Stage of HD & Treatment of HD & Outcome (duration of follow up) \\
\hline 9 & $32 / \mathrm{M}$ & 27 months & (ND) & (ND) & RT & Remission (ND) \\
\hline 10 & $59 / \mathrm{M}$ & 2 months & $\mathrm{CS}$ & $\mathrm{I} / \mathrm{II}$ & (ND) & Improved (3 months) \\
\hline 11 & $49 / \mathrm{F}$ & 7 months & $\mathrm{CS}$ & I/II A & RT & Remission (12 months) \\
\hline 12 & $46 / \mathrm{F}$ & 30 months & (ND) & (ND) & RT, HN-3 & Relapses (16 months) \\
\hline 13 & $68 / \mathrm{F}$ & $>2$ years & $\mathrm{CS}$ & IV & TEM & Died (3 months) \\
\hline 14 & $66 / F$ & Simultaneously & CS & IV & CS, TSPA & Died (11 months) \\
\hline 15,16 & $39 / \mathrm{F}$ & 3 months & CS & (ND) & RT & Died (10 months) \\
\hline 17 & $36 / \mathrm{M}$ & 5 months & CS & IVB & CS, chemo & Partial response (ND) \\
\hline 18 & $56 / \mathrm{F}$ & 8 months & CS & IIIS & MOPP, RT & Remission (8 months) \\
\hline 19 & $29 / \mathrm{M}$ & 5 years & CS & IV & RT, HN-3 & Died (9 years) \\
\hline 20 & $71 / \mathrm{M}$ & 13 months & (ND) & IIB & (ND) & $(\mathrm{ND})$ \\
\hline 21 & $48 / \mathrm{M}$ & 5.5 years & CS, MTX, CTX, AZA & IVB & MOPP, ABVD & Remission(12 months) \\
\hline 22 & $23 / \mathrm{F}$ & 20 months & CS & IVA & MOPP, ABVD & Remission (4 months) \\
\hline 23 & $24 / F$ & 3 months & CS & II & Chemo & Died (ND) \\
\hline 24,25 & $65 / F$ & 1year & CS, MTX & IVB & Withdrawal of MTX & $\begin{array}{c}\text { Remission } \\
\text { (1 year) }\end{array}$ \\
\hline 26 & $59 / \mathrm{F}$ & 1 year & $\begin{array}{l}\text { CS, IVIG, TAC, } \\
\text { MMF }\end{array}$ & (ND) & ABVD & Died (2 months) \\
\hline Index case & $30 / F$ & Simultaneously & CS & IV SB & ABVD & Improving ( 2 weeks) \\
\hline
\end{tabular}

Abbreviations: AZA - azathioprine, Chemo - chemotherapy, CS - corticosteroids, CTX -cyclophosphamide, HN-3 - nitrogen mustard, IVIG - intravenous immunoglobulin, MMF - mycophenolate mofetil, MOPP - nitrogen mustard/vincristine/procarbazine/prednisone, MTX - methotrexate, ND - not documented, RT - radiotherapy, TAC - tacrolimus, TEM -triethylenemelamine, TSPA - thiotepa/ triethylenethiophosphoramide. 
On follow up, six patient died, eight patients (and the index case) showed response to the treatment (complete or partial), one patient relapsed and in one case there was no documented outcome. As sufficient follow-up of the patients and adequate documentation is not available, the prognosis of patients with HD and DM could not be determined.

\section{Conclusion}

Patients with DM have a definite increase in the risk of cancer. A high index of suspicion and a search for cancer at regular intervals is therefore required. Abnormal findings in the medical history and physical examination warrant an extensive search for occult neoplasm including screening with a PET scan and invasive procedures.

\section{References}

1. Bohan A, Peter JB . Polymyositis and dermatomyositis (first of two parts). N Engl J Med. 1975;292(7):344 -347.

2. doi:10.1056/NEJM197502132920706.

3. Bohan A, Peter JB. Polymyositis and dermatomyositis (second of two parts). N Engl J Med 1975;292(8):403 -407. doi:10.1056/ NEJM197502202920807.

4. Chen YJ, Wu CY, Shen JL. Predicting factors of malignancy in dermatomyositis and polymyositis: a case-control study. $\mathrm{Br}$ Dermatol. 2001;144(4):825-831.

5. Hill CL, Zhang Y, Sigurgeirsson B, Pukkala E, Mellemkjaer L, Airio A, et al. Frequency of specific cancer types in dermatomyositis and polymyositis: a population-based study. Lancet 2001;357(9250):96100.

6. Maoz CR, Langevitz P, Livneh A, Blumstein Z, Sadeh M, Bank I, et al High incidence of malignancies in patients with dermatomyositis and polymyositis: an 11-year analysis. Semin Arthritis Rheum 1998;27(5):319-324

7. M. Fallah, Liu X, Ji J, Försti A, Sundquist K, Hemminki K. Autoimmune diseases associated with non-Hodgkin lymphoma: a nationwide cohort study. Ann Oncol 2014; 25: 2025-2030. doi: 10.1093/annonc/ mdu365.

8. Bei R, Masuelli L, Palumbo C, Modesti M, Modesti A. A common repertoire of autoantibodies is shared by cancer and autoimmune disease patients: Inflammation in their induction and impact on tumor growth. Cancer Lett. 2009;281:8-23. doi: 10.1016/j. canlet.2008.11.009.

9. Vajdic CM, van Leeuwen MT. Cancer incidence and risk factors after solid organ transplantation. Int J Cancer 2009;125(8):1747-1754. doi: $10.1002 / \mathrm{ijc} .24439$

10. Curtis AC, Blaylock HC, Harrell ER. Malignant lesions associated with dermatomyositis. J Am Med Assoc. 1952; 150(9):844-846.

11. Brunsting LA, Chistianson HB, Perry HO. Dermatomyositis: unusual features, complications, and treatment, AMA Arch. Derm. 1956;74(6):581-589.

12. Firmat J, Lipsett MB. Cancer and dermatomyositis. Cancer 1958;11(1):63-66.

13. Arundell FD, Wilkenson RD, Haserick JR. Dermatomyositis and malignant neoplasms in adults. A survey of twenty years' experience. Arch. Dermatol. 1960; 82:772-775.
14. Deep WD, Fraumeni JF, Tashima CK, Mcdivitt R. Leukoencephalopathy and dermatomyositis in Hodgkin's disease. A case report. Arch. Intern. Med.1964;113:635-640.

14. Miller DG. The association of immune disease and malignant lymphoma. Ann. Intern. Med. 1967;66(3):507-521.

15. Thiers H, Moulin G, Fayolle J, Tuaillon J. Acute dermatomyositis revealing Hodgkin's lymphoma, Lyon Med. 1969;221(16):954-957.

16. Thiers H, Moulin G, Fayolle J, Tuaillon J. Acute dermatomyositis revealing Hodgkin's Sarcoma Bull Soc Fr Dermatol Syphiligr. 1969;76(3):354-355.

17. Mosora N, Olteanu L, Dermkatomiozita paraneoplazica. Vlata. Med. 1970;17:999-1002.

18. Bosly A, Isaac G, Salamon E, Fievez C. Dermatomyositis revealed by Hodgkin'sdisease. Nouv. Rev. Fr. Hematol. Blood Cells. 1977;18(1):164-165.

19. Talbott JH. Acute dermatomyositis-polymyositis and malignancy Semin. Arthritis Rheum. 1977;6(4):305-360.

20. Novak Z, Biskupova H, Matznerova S, Vachtenheim J. Preneoplastic dermatomyositisand polymyositis, Fysiatr. Revmatol. Vestn. 1980; 58(1):41-46

21. Schwartz E, Friedman E, Engelberg S, Tomer A. Dermatomyositis and Hodgkin'sdisease. Case report and review of the literature. Isr. J. Med. Sci. 1985;21(12):988-991.

22. Dowsett RJ, Wong RL, Robert NJ, Abeles M. Dermatomyositis and Hodgkin's disease. Case report and review of the literature. Am. J. Med. 1986;80(4):719-723.

23. Schulman P, Kerr LD, Spiera H. A re-examination of the relationship between myositis and malignancy. J. Rheumatol. 1991;18(11):16891692.

24. Kamel OW, van de Rijn M, Weiss LM, Del Zoppo GJ, Hench PK, Robbins BA, et al. Brief report: reversible lymphomas associated with EpsteinBarr virus occurring during methotrexate therapy for rheumatoid arthritis and dermatomyositis. N. Engl. J. Med. 1993;328(18):13171321. doi:10.1056/NEJM199305063281806.

25. Kamel OW1, van de Rijn M, LeBrun DP, Weiss LM, Warnke RA, Dorfman RF. Lymphoid neoplasms in patients with rheumatoid arthritis and dermatomyositis: frequency of Epstein-Barr virus and other features associated with immunosuppression. Hum. Pathol. 1994;25(7):638643.

26. Selva-O'Callaghan A, Palacios A, Solans-Laque R, Labirua A, SalcedoAllende T, Vilardell-Tarrés M. Epstein-Barr virus associated lymphoma in patients with dermatomyositis. Be aware of double immunosuppression. Rheumatology (Oxford). 2009; 48(11): 14621463. doi: 10.1093/rheumatology/kep247.

27. Johnson NE, Arnold WD, Hebert D, Gwathmey K, Dimachkie MM, Barohn $\mathrm{RJ}$, et al. Disease course and therapeutic approach in dermatomyositis: a four-center retrospective study of 100 patients. Neuromuscul. Disord. 2015;25(8):625-631. doi: 10.1016/j.nmd.2015.04.013.

28. Ishizuka M, Watanabe R, Ishii T, Machiyama T, Akita $\mathrm{K}$, Fujita Y, et al. Long-term follow-up of 124 patients with polymyositis and dermatomyositis: statistical analysis of prognostic factors. Mod. Rheumatol. 2016;26(1):115-120. doi: 10.3109/14397595.2015.1054081.

29. Aggarwal R, Oddis CV. Paraneoplastic myalgias and myositis. Rheum. Dis. Clin. N. Am. 2011;37(4):607-621. doi: 10.1016/j.rdc.2011.09.007. 